\title{
A TRANSPARÊNCIA DA FÉ: TRÊS CAPELAS (PARTICULARES) DE CONTEMPLAÇÃO NO BRASIL
}

\section{SUGAWARA, KATIA RODRIGUES GUERREIRO}

\author{
Mestranda, Universidade Presbiteriana Mackenzie, kguerreirosgw@gmail.com
}

\section{PERRONE, RAFAEL ANTONIO CUNHA}

\author{
Livre-docente, Universidade Presbiteriana Mackenzie, racperrone@gmail.com
}

\begin{abstract}
RESUMO
O espaço para encontrar Deus é silencioso, misterioso e natural como que se dele emanasse a presença do próprio Deus, na arquitetura, os vãos permitem a mostra da obra criada pelo Senhor - a natureza. "Deitar-me faz em verdes pastos, guia-me mansamente a águas tranquilas" [Salmos 23:2] cita Davi em seus Salmos, apresentando a natureza como que sagrado e berço divino. O espaço sacro não trata somente do espaço destinado aos ritos, mas do local de encontro com o sagrado, através da introspecção, adoração e contemplação. Este artigo consiste no estudo do espaço de três capelas particulares, projetadas e construídas entre 1980 e 2015, por meio da análise gráfica e dos simbolismos. O propósito é analisar a arquitetura destes espaços, nos quais fanum e profanum se completam e pelo qual a arquitetura do homem e a obra de Deus (espaço natural) constituem o espaço sagrado, à luz da relação entre a transparência arquitetônica e as paisagens naturais que corroboram na experiência da sacralidade do espaço vinculada à permeabilidade visual.

PALAVRAS-CHAVE: capelas; arquitetura religiosa; espaço sacro; contemplação.
\end{abstract}

\section{RESUMEN}

El espacio para encontrar a Dios es silencioso, misterioso y natural como si de él emana la presencia de Dios mismo, en la arquitectura, los vanos permiten la muestra de la obra creada por el Señor - la naturaleza. "Acostarse en verdes pastos, quíame mansamente a aguas tranquilas" [Salmos 23: 2] cita a David en sus Salmos, presentando la naturaleza como sagrado y cuna divina. El espacio sacro no trata solamente del espacio destinado a los ritos, sino del lugar de encuentro con lo sagrado, a través de la introspección, la adoración y la contemplación. Este artículo consiste en el estudio del espacio de tres capillas particulares, proyectadas y construidas entre 1980 y 2015, por medio del análisis gráfico y de los simbolismos. El propósito es analizar la arquitectura de estos espacios, en los cuales fanum y profanum se completan y por el cual la arquitectura del hombre y la obra de Dios (espacio natural) constituyen el espacio sagrado, a la luz de la relación entre la transparencia arquitectónica y los paisajes naturales que corroboran en la experiencia de la sacralidad del espacio vinculada a la permeabilidad visual.

PALABRAS CLAVES: capillas; arquitectura religiosa; espacio sacro; contemplación.

\section{ABSTRACT}

The space to find God is silent, mysterious and natural as if from the emanation of God's own presence in architecture, spans allow the show of the work created by the Lord - nature. "He maketh me to lie down in green pastures, He leadeth me beside the still waters" [Psalm 23: 2] quotes David in his Psalms, presenting nature as sacred and divine cradle. The sacred space is not only about the space destined for the rites, but the place of encounter with the sacred, through introspection, adoration and contemplation. This article consists of the study of the space of three private chapels, designed and built between 1980 and 2015, through graphic analysis and symbolism. The purpose is to analyze the architecture of these spaces, in which fanum and profanum are completed and by which the architecture of man and the work of God (natural space) constitute the sacred space, in the light of the relationship between architectural transparency and natural landscapes corroborate in the experience of the sacredness of space bound to visual permeability.

KEY-WORDS: chapels; religious architecture; sacral space; contemplation.

\section{INTRODUÇÃO}

A produção religiosa é tema recorrente e constante da produção arquitetônica. Geralmente de arquitetura notável e majestosa, os templos religiosos, se apresentam carregados de símbolos, formas e conceitos do espaço temporal em que foi produzido. No Brasil, não obstante, esta produção arquitetônica também se fez relevante à história, todavia inicialmente apresentou-se em proporções menores e deveras em espaços recônditos. Este espaço de pequena dimensão dedicado a ritos religiosos, aqui definidos como Capela, esteve presente na história do Brasil a partir da colonização portuguesa, sociedade majoritariamente católica na época. As capelas, no entanto, apresentavam-se como anexos ou complementos às edificações - de uma propriedade rural ou de um colégio. A religiosidade era vivida a nível doméstico e familiar, uma fé intimista, impregnada de profunda devoção, que trazia junto a si padroeiros e imagens para serem vinculadas ao espaço social da habitação. De acordo com Mott (1997), havia uma dicotomia ritual na fé portuguesa, na qual de um lado o exercício individual e privado de comunicação direta entre a imagem com 
sua semelhança, de outro a rotina pública dos sacramentos, constando a coexistência de duas práticas religiosas: a contemplatio e a Liturgia.

A contemplatio aproximava a religião proclamada da fé individual e intimista, resultando numa profunda confraternização de valores e sentimentos, uma religião "doce, doméstica" - como citado por Freyre (2003, p. 227). A proximidade religiosa e doméstica entre os fiéis e o santo padroeiro era vista nas adulações das imagens, relicários e oratórios ornamentados em ouro e suas capelas particulares. No entanto, não poderiam ser instaladas igrejas particularmente para satisfazer o desejo e religiosidade de cada família. $O$ fanum $^{1}$ e o profanum ${ }^{2}$ não poderiam estar imersos num mesmo ambiente, a segregação espacial era diretriz para a instalação de um espaço devocional externo à igreja. As famílias mais abastadas, situadas em meio rural, não podendo frequentar a cidade e a igreja matriz regularmente, teriam que manter a tradição católica e a comunhão com Deus. O altar interno e a capela que complementavam o programa residencial garantiam as práticas religiosas. As instituições educacionais, originalmente vinculadas à religião e em sua maioria estabelecidas por jesuítas, também agregavam as capelas em suas dependências.

Neste contexto, observa-se o profundo vínculo entre a religião, aqui destacando as capelas, e a história do Brasil. Cinco séculos distam destas origens, no entanto, a produção arquitetônica de capelas como edificações anexas ainda são recorrentes e atuais. Obviamente, o objetivo destes espaços já no mundo moderno e contemporâneo, não trata da organização social de uma família, um grupo social, um povoado ou região. Tampouco se faz obrigatória para garantir o cumprimento de rituais litúrgicos. $O$ apelo da arquitetura sagrada é então destinado a outros fins que não a aproximação de fiéis e a promoção dos ritos sagrados dominicais, embora mantenha, dentre outras, a tarefa de conectar o homem com Deus por intermédio da dialética arquitetônica, onde o espaço e o vazio arquitetônico conduzem à aproximação, ao reconhecimento e ao encontro do divino através da introspecção, adoração e contemplação.

Dentro deste contexto, este artigo se propõe a analisar três capelas cujo caráter de contemplação é dominante, uma vez que a transparência se apresenta como artifício de comunicação entre os espaços fanum e profanum, humano e divino. A transparência da arquitetura sagrada é a chave da contemplação, que corrobora na experiência da sacralidade do espaço vinculada à permeabilidade visual, onde a paisagem natural e arquitetura compõem a obra religiosa.

As capelas anexas, construídas durante os tempos mais contemporâneos, mantêm a sua relação com os espaços familiares de residências de campo e se destinam a manter as práticas íntimas de contato com a religiosidade e a possibilidade de introspecção e meditação. Importa esclarecer que trataremos de capelas anexas, como objetos que fazem parte de um conjunto. Sendo tal caracterização fundamental ao entendimento de que não se trata de um objeto arquitetônico cujo objetivo seja tão somente sua obra, mas sim inserido no meio posteriormente uma construção principal, quer seja ela uma residência, uma instituição ou edifícios de fazenda. Sendo que estas, em sua maioria de caráter particular, têm grande liberdade projetual e arquitetônica e, portanto, desempenham papel significante na arquitetura atual.

O objeto estudado há que ser de caráter religioso, católico, de pequenas dimensões, desprovido de líder residente (padre/ pastor/ reverendo), complementar ao programa de uma residência de campo ou exercendo uma função como apêndice a uma instituição. A exclusividade da denominação católica deu-se em função do maior número de exemplares encontrados e necessária unidade litúrgica. $O$ estabelecimento de tais parâmetros foi fundamental para analisar comparativamente os estudos de caso, de forma que não se equipare um templo ou paróquia com capela, visto as dissemelhanças no espaço litúrgico, programa arquitetônico e funcionalidade.

As leituras e análises espaciais e simbólicas são determinantes na construção de um repertório e como formadoras de posição crítica e conhecimento teórico sobre o tema abordado. A análise destes projetos e obras, no entanto, não consiste apenas no olhar, mas exige uma visão que inclui reflexionamento.

\section{TRÊS CAPELAS DE CONTEMPLAÇÃO}

A leitura projetual será pautada pelo referencial teórico, no qual autores como Baker (1998), Ching (2008), Unwin (1997), Clark e Pause (1997), entendem a diagramação como elemento necessário à análise. Também a decomposição do desenho é método relevante para a análise, pois permite um olhar segmentado do todo. A análise considera, ainda, o partido arquitetônico adotado ou revelado pelas observações realizadas, que, por sua vez, refletem as condicionantes do projeto, tais como a técnica construtiva, o clima, as condições do terreno, o programa de necessidades, as condições financeiras e a legislação. No caso das capelas incluem-se, ainda, as intenções de manifestação do caráter espiritual.

\section{Capela Tatuí}


A Capela Tatuí, assim identificada neste estudo, situa-se na cidade que a nomeia, no interior do Estado de São Paulo, anexa a uma residência rural, portanto, de caráter privado. Projetada pela arquiteta Beatriz Meyer em 2006, e construída no mesmo ano, foi encomendada pelos proprietários da fazenda, cuja intenção era ter um local particular para encontrar paz em meio à natureza.

A simplicidade projetual e estrutural permitiram que a construção não levasse mais do que três meses. A capela foi erguida em três etapas independentes, sendo primeiro a fundação e o contrapiso, seguidos da parede de pedra e da estrutura em madeira, finalizada com o forro e cobertura também em madeira, além dos caixilhos de vidro.

A capela de $70 \mathrm{~m}^{2}$ está implantada sobre um platô, entre duas fileiras de pinheiros em meio à vegetação da fazenda com cerca de $10.000 \mathrm{~m}^{2}$. O conjunto arquitetônico é composto por estrutura em madeira de cumaru, parede de pedra e vedação em vidro. A permeabilidade visual, a integração e a harmonização com a natureza eram premissas do projeto arquitetônico. A estrutura de madeira já havia sido utilizada nas edificações pré-existentes no terreno, no entanto o arranjo estrutural independente dos caixilhos de vidro mostrou-se inovador e agregou leveza à capela. Inclinada, a cobertura forrada por madeira dá amplitude ao átrio e intimidade ao presbitério, além de conduzir a visão do espectador ao altar.

O programa litúrgico proposto é composto basicamente por três setores, em ordem de acesso: átrio, nave e presbitério. A planta arquitetônica da capela é livre de mistérios e complexidades, sendo o perímetro da edificação desenhado por um retângulo encaixado entre a vegetação, alcançando quase total permeabilidade visual no espaço, não fosse pela parede de pedra que enquadra o altar - única fronteira visual dentre as quatro faces que encerram a capela. Implantada sobre um platô, é rodeada por um calçamento de tijolo de junta seca, cinco centímetros abaixo do nível do assoalho da edificação. A cobertura de madeira cumaru, extremamente delgada, está apoiada sobre oito pilares cilíndricos, quatro vigas transversais e 19 vigas longitudinais em madeira, ligados por conectores metálicos. Forrada internamente por ripas de madeira.

Figura 1: Vista frontal da Capela Tatuí.

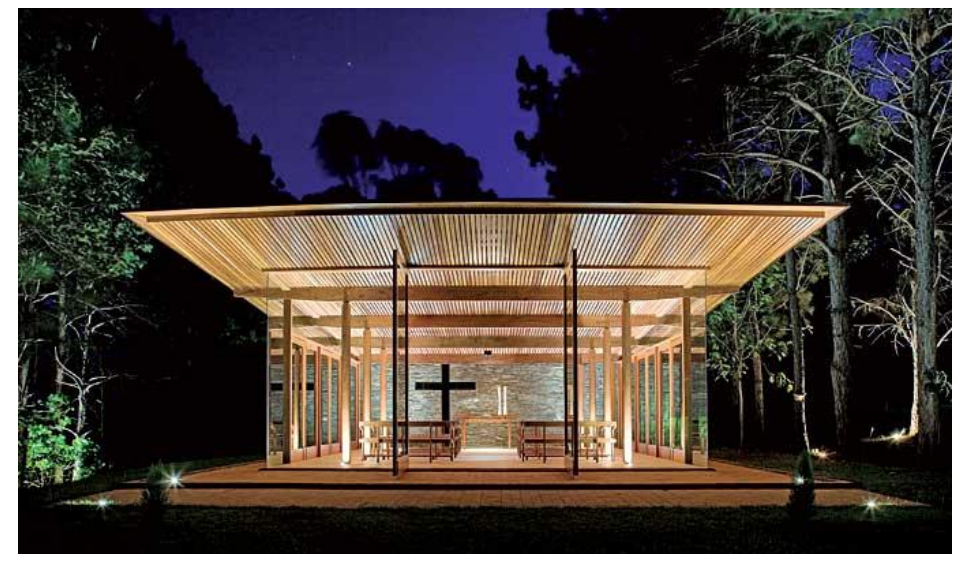

Fonte: Revista Projeto Design ${ }^{3}$.

O gabarito de altura máximo da edificação é alcançado, pela cobertura inclinada, sobre a área do átrio cuja amplitude do pé-direito chega a $3,60 \mathrm{~m}$, todavia ainda assim encontra-se abaixo das copas dos pinheiros. A variação do pé-direito é linear e reduz-se à altura mínima de 2,60m sobre o presbitério, culminando na parede de pedra que encerra a face sudoeste do conjunto.

As demais faces do retângulo, que formam a capela, são compostas por caixilhos de madeira e vidro, cuja permeabilidade não é apenas visual, mas física. A capela possui sete portas, sendo três em cada face lateral (noroeste e sudeste) e uma, maior que as outras, para a face nordeste - entrada principal, que faz a fachada da edificação. A quantidade de portas é notória vista a dimensão da capela e a lotação estimada, que é de apenas 24 pessoas. Os assentos, igualmente à estrutura, piso e cobertura, são de madeira.

A ornamentação fica à mercê dos revestimentos e da iluminação. A simplicidade projetual faz com que a arquitetura se encerre em si, de maneira a não requerer detalhes além da estrutura, parede e caixilhos. Sendo a iluminação ponto final da obra, a fim de evidenciar a arquitetura sacra e o mistério religioso.

A análise gráfica se desenvolveu em cima da planta, corte e fachada da edificação, que manipuladas permitiram identificar algumas características desta arquitetura.

Implantação e perímetro: Situada em um platô, entre duas fileiras de pinheiros como representado pelos eixos que norteiam a implantação da capela, a integração e harmonia com a natureza traçaram o partido 
desta arquitetura. O eixo linear dos pinheiros é paralelo às laterais e direciona o alinhamento dos quatro pilares em cada lado da nave, internos à edificação. A inclinação da cobertura dá perspectiva à capela, imponência à entrada evidenciando o local sagrado e conduz o olhar ao altar. A capela é elevada em $10 \mathrm{~cm}$ em relação ao perfil do terreno, sendo $5 \mathrm{~cm}$ o piso de tijolo e mais $5 \mathrm{~cm}$ o piso que conduz à nave. $A$ implantação não segue o eixo Leste-Oeste, mas tem sua fachada principal voltada para a face mais insolada.

A permeabilidade visual atravessa a nave transversalmente, passa por entre os assentos, pilares e portas até alcançar novamente os pinheiros dos outro lado. Longitudinalmente essa permeabilidade dá se desde 0 acesso até o altar, porém é barrada pela parede de pedra e permeia pelo estreito vão que forma a imagem da cruz. Pela cruz vazada na parede vê-se a natureza do lado de fora novamente. A cobertura situa-se abaixo da copa dos pinheiros e a sequencia dos caules dispostos enfileirados, juntamente com a inclinação da cobertura dão perspectiva e profundidade à capela.

Espaço e organização: o espaço interno está organizado de forma bem simples e objetiva, sendo composto por três espaços: (1) o átrio, quase externo à edificação, pois não está protegido pela vedação lateral em vidro, mas situa-se sob a cobertura de madeira. A marcação no piso pelo desnível permite identificar com clareza este espaço; (2) a nave, situada desde o acesso até um pouco a frente do terceiro pilar, cujo limite físico entre nave presbitério é inexistente, deixado à percepção do visitante em razão do mobiliário, vazios e elementos litúrgicos; e, (3) o presbitério, situado sob o pé-direito mais baixo $(2,60 \mathrm{~m})$ alinhado entre dois pilares e moldurado pela parede de pedra ferrugem, que abriga o altar e o crucifixo.

Acessos e circulação: há três acessos possíveis à capela, sendo três portas em cada lateral que compõem dois dos três acessos e um pela porta única principal que compõem a fachada. A circulação interna é delimitada pela disposição do mobiliário e pelos pilares internos. A capela é simétrica e a circulação também.

Geometria e estrutura: estrutura é de madeira, proveniente de cultivos sustentáveis, independente do fechamento em vidro e apoiada em pilares sob vigas transversais que sustentam a estrutura da cobertura encerrada sobre vigas longitudinais também em madeira. As partes são ligadas por conectores metálicos que as distanciam e criam a sensação de leveza. As tramas da estrutura da cobertura e da paginação do assoalho compõem uma malha num plano ortogonal.

Forma e volume: a sobreposição de retângulos formam a planta e a elevação, orientados por eixos paralelos e simétricos, numa perspectiva que conduzida pela cobertura inclinada direciona ao centro da capela - 0 altar. O crucifixo, no entanto, destoa esta simetria, situado à esquerda do eixo central da capela na parede de pedra. Apesar da forma retangular, a inclinação da cobertura faz com que a percepção do volume como um todo não seja tão óbvio, mas orienta um movimento e a perspectiva interna, percebido principalmente pela alternância dos materiais que compõem o conjunto de cheios e vazios.

Figura 2: Diagramas da planta e elevação frontal.

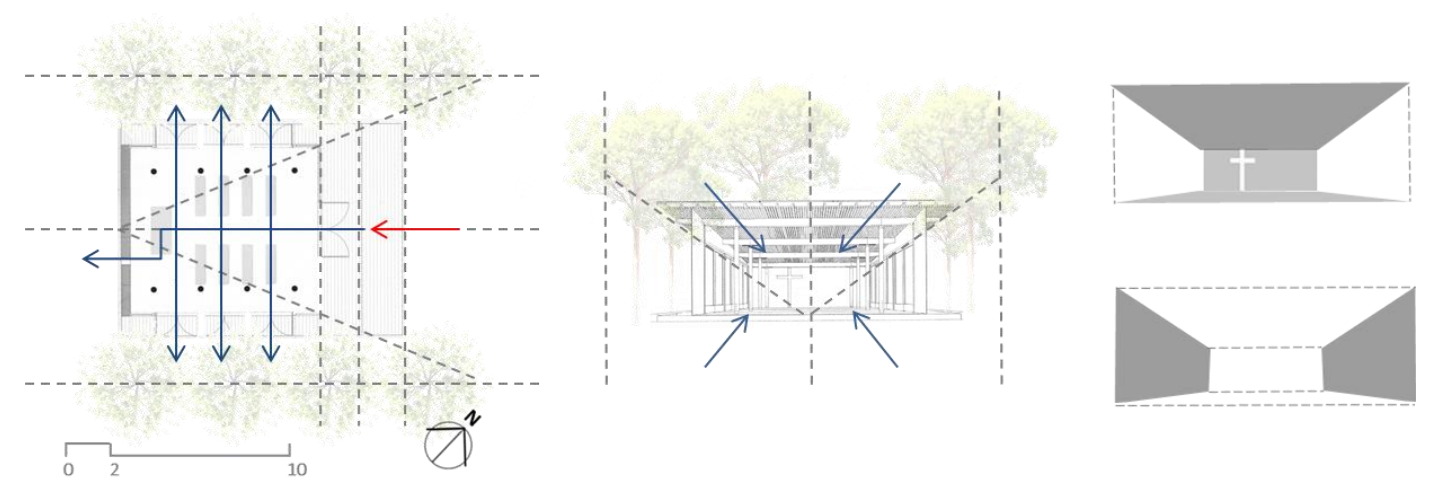

Fonte: Revista Escala ${ }^{4}$, editado pela autora.

Analogias e Metáforas: Construída como refúgio de paz em meio à natureza de uma fazenda em Tatuí, a arquitetura da capela traz consigo o caráter sacro do cristianismo através da simplicidade e leveza, composta em conjunto com a própria obra divina - a natureza. A materialidade, a forma, a permeabilidade visual e a iluminação formam o caráter religioso e metafórico deste espaço.

A madeira, não tão somente como característica da arquiteta que projeta a capela e como objeto de integração ao meio, traz à capela simplicidade. $\mathrm{O}$ assoalho com madeira de demolição e a estrutura em madeira de reflorestamento, com pequenas variações de tonalidade agregam unidade e simplicidade à forma. A estrutura delgada e desligada da vedação garante leveza ao conjunto, tal como deve ser a paz - 
simples e leve. E os pilares dispostos paralelamente, conforme observado pela própria arquiteta em entrevista à ArcoWeb (ed.333, 2007), remetem aos caminhos que conduzem ao altar, tal como nos templos egípcios.

Ao fundo a parede em pedra, vazada pela imagem da cruz pode representar tanto a solidez da fé, como o santo sepulcro. A solidez da fé, por que a pedra como material sólido que permeia pelo tempo emoldura o altar e faz do vazio a imagem da cruz, como o cristo ressuscitado que não abriga, nem carrega mais a cruz, sendo esta apenas uma memória do percurso em vida. E o santo sepulcro, pois conforme consta nas sagradas escrituras, de acordo com Lucas 23: 53, Jesus após ter seu corpo retirado da cruz, foi envolto num lençol de linho e depositado num "tumulo aberto em rocha".

A transparência do vidro permite a contemplação da obra divina, da natureza e a integração entre o fanum e profanun. Os espaços são separados fisicamente, mas integrados visualmente, a estrutura e o meio compõem a arquitetura da capela, que não se encaixaria tão bem em outro sítio ou vizinhança, devido composição em relação à vegetação. A transparência, o vazio do crucifixo na parede de pedra é item relevante como metáfora, pois a transparência e permeabilidade visual livres na capela são barradas na parede de pedra, permitida no presbitério somente através da passagem pela cruz. Tal situação remete à outra passagem bíblica citada em João 13:6 "Respondeu-lhe Jesus: Eu sou o caminho, e a verdade, e a vida; ninguém vem ao Pai senão por mim". Assim só seria possível passar pelo sepulcro e alcançar aos céus, ora representado pela natureza, por meio da cruz. O sacrifício, representando pela mesa do altar, permite a passagem pela cruz.

Por fim, destaca-se a iluminação disposta no piso somente com um ponto de luz no teto sobre o altar. Na vista noturna, esta iluminação "debaixo para cima" cria um clima de mistério e a iluminação mais intensa sobre o altar destaca o local da santidade.

\section{Capela Fazenda Veneza}

Projetada por Décio Tozzi em 2012 e construída no mesmo ano, a capela de $225 \mathrm{~m}^{2}$ está localizada em um declive à beira do lago da Fazenda Veneza, propriedade particular (residência) na cidade de Valinhos/SP. $\mathrm{O}$ arquiteto marca e define a capela em apenas dois elementos "a capa curva de concreto e a cruz de Cristo", como Décio mesmo cita em descrição publicada nas "Actas del Congreso Internacional de Arquitectura Religiosa Contemporánea 4 (2015)":

\footnotetext{
Dos elementos plásticos señalam um lugar em el paisaje.

Dos signos de ressonância profunda.

Uno, la cobertura curva, abrigo de hormigón.

Outro, la cruz de Cristo.

Se acrecienta el paisaje.

El espacio del templo y el espacio de la naturaleza.
}

Figura 3: Vista frontal da Capela Fazenda Veneza.

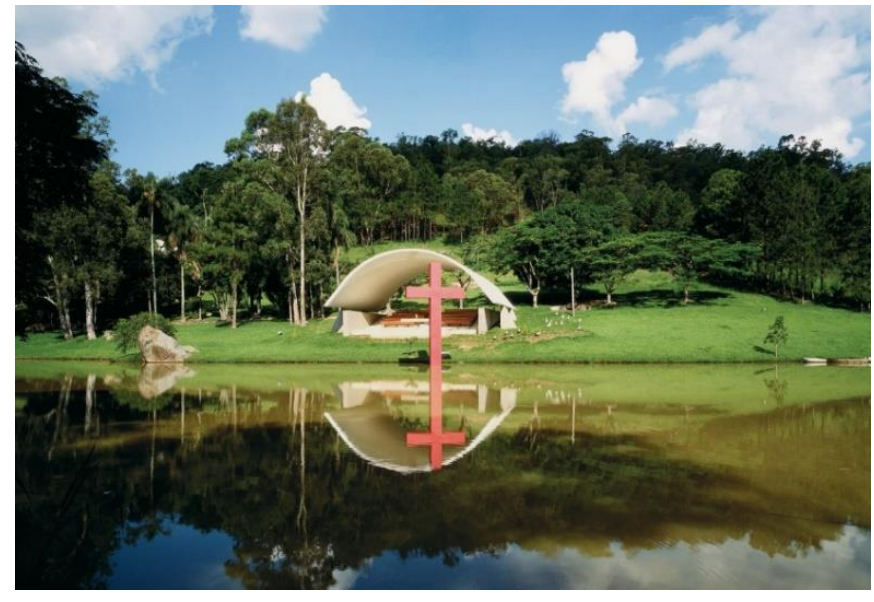

Fonte: Archidaily ${ }^{5}$.

A cobertura de concreto e o crucifixo desenham a arquitetura da capela na margem e no próprio lago, o reflexo não é ocasional, mas esperado. A água é elemento de composição e ambientação da arquitetura que se faz em conjunto com a paisagem, com a natureza.

O espaço arquitetônico foi criado com intuito de promover a meditação religiosa, onde o caráter sacro e profano coexistisse, um espaço de culto, porém aberto. A arquitetura é aberta, exposta, integrada à 
natureza, à paisagem. Composta por uma casca curva de concreto, que repousa sobre quatro apoios também de concreto, o espaço da capela é delimitado por dois arrimos laterais revestidos de pedra e pelo piso que marca o espaço desde o átrio até o altar, na cota mais baixa do terreno e mais próxima ao lago. $O$ crucifixo disposto assimetricamente no lago compõe e emoldura o altar em conjunto com a paisagem.

$O$ concreto e a pedra definem a materialidade utilizada na arquitetura, sendo madeira utilizada apenas no mobiliário. A iluminação está encravada na parede de pedra, que ilumina todo o côncavo da cobertura, que irradia luz, sem a projetar, mas só em refletir. O programa litúrgico é composto por átrio, batistério (pia batismal), nave, presbitério com altar (mesa) e crucifixo, externo - no lago. A nave em declive é resultado do perfil natural do terreno que margeia o lago. As montanhas e arvores ao fundo compõem o átrio; o lago, a vegetação da outra margem e o céu emolduram o altar.

Implantação e perímetro: Em declive, tal como a margem do lago, a nave se acomoda e abre visão para o ator principal que é a vista para o lago. Os eixos das muretas e o apoio da cobertura marcam a o sentido visual pretendido, que apesar de grande permeabilidade é único, do átrio para o altar, de forma que não há permeabilidade visual nas laterais da capela. A assimetria é marcada pelo eixo do crucifixo que se aproxima da orientação Leste-Oeste, posicionando-se em direção ao extremo leste da capela.

Espaço e organização: A planta é composta por um retângulo aparado por muretas laterais de pedra. O declive é parte integrante da nave que culmina num platô, na menor cota de nível da capela, onde se situa o altar. Fora da cobertura, quase a dez metros de distância do altar está o crucifixo, vermelho. $O$ batistério situa-se no átrio e ao seu lado está uma imagem. $O$ átrio abriga o menor pé-direito e a maior cota do terreno.

Acessos e circulação: $O$ acesso à capela se dá somente pelo átrio num caminho situado a oeste da capela e, a circulação por entre o mobiliário (assentos) em direção ao altar a leste da capela. A partir do altar não há qualquer acesso ou circulação interligada à área externa. $\mathrm{O}$ acesso é único, livre de portas e quaisquer vedações, e está definido pela própria implantação em relação o perfil do terreno e delimitação do piso.

Geometria e estrutura: A cobertura é um único côncavo em concreto, sustentado por quatro apoios também de concreto em formato de triângulo retângulo. Importa observar que a cobertura não toca as muretas de pedra, mas paira sobre elas. As partes são independentes e não há vedação lateral. A arquitetura é simétrica, exceto pelo crucifixo que destoa à esquerda do altar para quem olha da nave, também em eixo angular em relação aos demais, que são paralelos às muretas e cobertura.

Forma e volume: a capela é um volume único e de formas puras, sendo a planta quase um quadrado, o corte um retângulo e a vista um arco. O volume, também identificado pelo negativo entre cheios e vazios, revela a arquitetura "quase imaterial" como descrita pelo arquiteto ${ }^{3}$ composta de poucas linhas, nenhuma vedação e grande permeabilidade visual.

Figura 4: Diagramas da planta, corte e elevação.

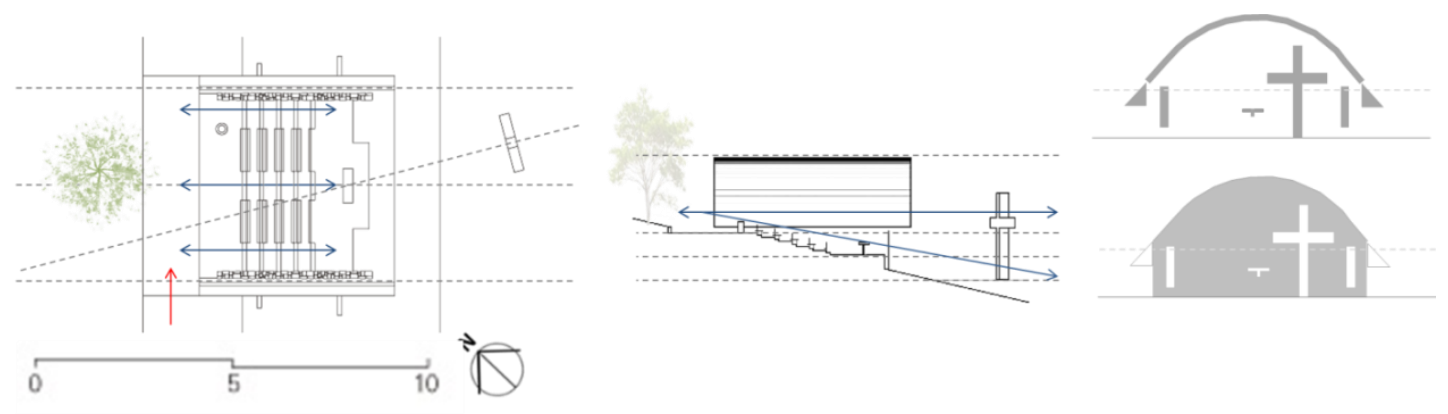

Fonte: Archidaily ${ }^{3}$, editado pela autora.

Analogias e Metáforas: A proximidade da capela com o lago é proposital e almejada pelo arquiteto desde o croqui inicial, onde há a representação da cobertura e do crucifixo invertidos como reflexo no lago. Tal como a paisagem da natureza ao redor, a água inevitavelmente compõe a arquitetura desta capela. Em muitas culturas e em especial para a cristã, a água possui um significado de vida, purificação e renascimento. Assim, o crucifixo sobre a água, evidencia a ressurreição de Cristo, que vive que renasceu.

A cobertura faz referencia à origem da palavra capela (do latim), que denota o manto de proteção levado pelos guerreiros em suas batalhas. A curva da cobertura revela o infinito dos céus, sem cantos, sem 
começo ou fim, uma atmosfera que paira sobre o homem. Nota-se que os apoios triangulares sobre o qual paira a cobertura estão escondidos atrás da mureta de pedra que quando observados de dentro da capela são imperceptíveis, ressaltando a leveza da cobertura.

A iluminação de baixo para cima, iluminando o côncavo do teto na nave surge, na visão noturna, como uma fonte de luz que parece imanar do próprio concreto, uma luz divina, que é dada pela capela. $O$ piso em pedra revela a terra firme habitada pelo homem e também a integração com a natureza.

A capela exposta e ao mesmo tempo intimista traz à tona a fé de contemplação, onde a proximidade e contato com o divino se dá por intermédio da revelação da natureza, da observação da própria obra de Deus, da simplicidade tal como é a sua própria arquitetura.

\section{Capela Fazenda Santa Helena}

A capela projetada em 2010 pelo escritório B\&L Arquitetura foi construída em 2012, na fazenda Santa Helena, em Bom Despacho/MG. Um espaço de formas puras e retas, construído em concreto armado e pedra, abrigava a ideia inicial cuja simplicidade e exaltação da natureza foram elementos do partido para a arquitetura.

Em meio ao campo aberto da fazenda, maior produtora de feno do país - o capim Tifton 85, os arquitetos buscavam uma arquitetura descomplicada e de formas puras, cuja ideia central era valorizar a "imensidão da paisagem circundante e propiciar momentos de paz e contato com o divino", diz a equipe do B\&L à ArcoWeb (edição 403). Havia também a preocupação em evidenciar as origens da fazenda e das vilas coloniais da região mineira, bem como das tradições religiosas, o que se fez possível por intermédio dos materiais aplicados: a pedra e a madeira de demolição.

Duas paredes de concreto, revestidas em pedra, apoiam a laje que abriga a pequena nave e recorta a paisagem que faz o pano de fundo do altar. Sutil e delicado, o crucifixo, em conjunto com o altar (mesa), dá $\mathrm{o}$ tom religioso à arquitetura.

Figura 5: Vista frontal da Capela da Fazenda Santa Helena.

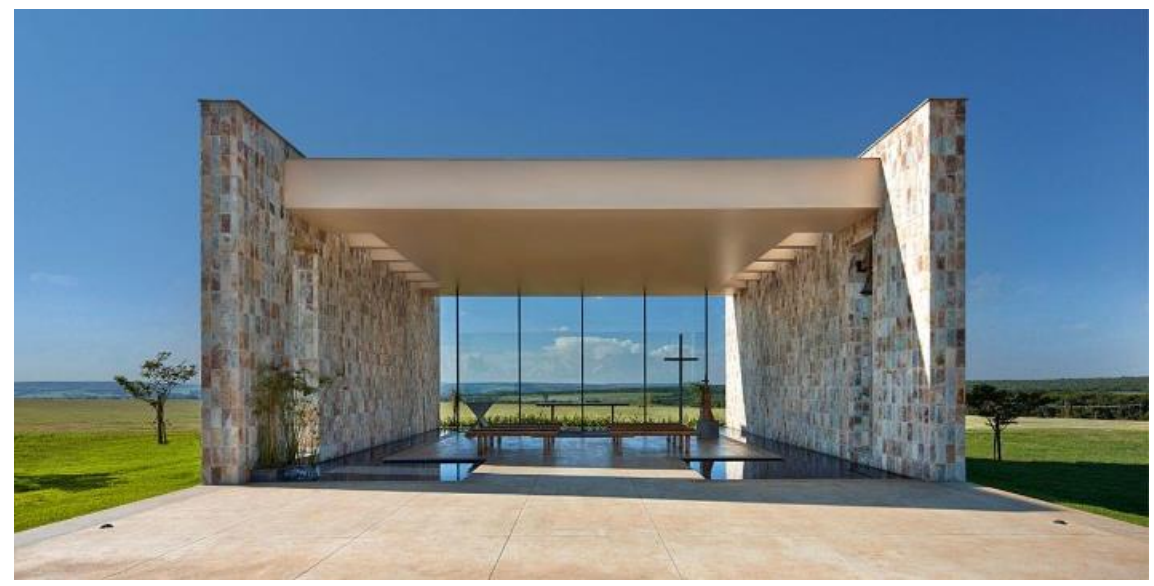

Fonte: designbh.wordpress ${ }^{6}$.

Implantada num grande plano em meio à imensidão da fazenda Santa Helena, a capela com $150 \mathrm{~m}^{2}$ é arquitetura contemporânea, de formas puras, retas e sobreas que remete à tradição dos edifícios religiosos por intermédio da materialidade aplicada. Um programa litúrgico repleto de elementos e símbolos compõe a capela, de forma que todos os rituais possam ser executados, no entanto, sem pesar sobre a arquitetura a ordem do espaço destinado aos rituais religiosos.

Três peças definem a capela: as paredes laterais revestidas em pedra e a laje recortada apoiada sobre estas. No entanto, é o piso que dá o tom ao espaço, que marca a área da capela, que a segrega sutilmente do entorno imediato. As paredes laterais apresentam uma fresta ainda no átrio que permitem a entrada de luz e é a única permeabilidade visual no sentido lateral da nave. A laje, também contem aberturas, cinco de cada lado, que permitem a entrada da luz natural. Não há qualquer porta ou restrição ao acesso da capela no átrio, que é completamente aberto e livre de vedações. Já o altar é encerrado por um pano de vidro, estruturado em perfis metálicos pretos, que não alcança a laje e permite a ventilação natural cruzada. $O$ piso majoritariamente é revestido em porcelanato e madeira de demolição sob o altar. Um espelho d'água margeia a nave e abraça o altar. 
Implantação e perímetro: Dois eixos paralelos, sentido norte-sul, marcam o posicionamento da capela no sítio, delimitados pela projeção da cobertura e estendidos pelo prolongamento do piso. A permeabilidade visual se dá no mesmo sentido, explorada nas laterais através de pequenas frestas verticais nas paredes do tênue espaço ocupado pelo átrio.

Os eixos em planta repetem-se nos eixos da elevação, sendo ambas retangulares e delimitadas pelas paredes de concreto. Ao norte, na fachada de maior insolação, está o altar e ao sul o átrio.

Espaço e organização: O programa litúrgico é composto por átrio, nave e presbitério que abriga o altar (mesa), o crucifixo, a pia batismal e uma imagem. O campanário está localizado na abertura da parede lateral de concreto, revestida em pedra. A organização espacial da capela não destoa da organização litúrgica corriqueira e agrega o batistério ao lado do altar. O altar situa-se na fachada de maior insolação e é abraçado pelo espelho d'água que segue pela nave até o limite do átrio sob a cobertura da laje.

Acessos e circulação: $O$ acesso à capela se dá somente pelo átrio num caminho que parte da face sul, primeiramente descoberto e aberto à fazenda. Sob a laje, o átrio toma sua menor dimensão, estreita-se numa passagem entre o espelho d'água e depois acessa a nave. Neste mesmo ponto de estreitamento as paredes laterais se abrem, num pequeno vão, cuja permeabilidade é apenas visual. Não há transposição a partir do altar.

Geometria e estrutura: A capela é formada por um único volume, bem delimitado e marcado na paisagem, resultado de duas paredes paralelas de concreto, coberta pela laje com aberturas zenitais. A laje está estruturada em oito vigas de concreto dispostas paralelamente entre si e perpendicularmente às vigas que se apoiam, sobre as paredes. A geometria é simétrica, retangular, repetida entre planta e elevação.

Forma e volume: Os recortes da laje e do piso rompem a obviedade da volumetria retangular da capela, que segue eixos paralelos e perpendiculares encerrando a forma, sem ângulos ou assimetrias. Destoa apenas o crucifixo à direita do eixo central onde se situa o altar. O volume é majoritariamente um vazio, preenchido pela paisagem emoldurada na forma da capela. As paredes e laje, no entanto, dão perspectiva ao pano de fundo e direcionam o olhar. O piso de certa forma também contribui para esta perspectiva uma vez que se estende além no átrio numa pequena esplanada que precede a capela, como se orientasse de que local a capela deve ser vista, já que não há acesso ou passagem ao redor da outras faces da capela.

Analogias e Metáforas: A simplicidade e pureza das formas novamente se faz presente como elemento sacro da arquitetura, cuja intenção é evidenciar a beleza da natureza que circunda o pequeno templo e fazer desta o objeto principal de apreciação, onde a arquitetura se torna o meio para evidenciar a contemplação e introspecção pretendida. A materialidade agrega valor no quesito pureza e simplicidade. A pedra, a madeira e a água fazem parte tanto da arquitetura religiosa colonial de Minas Gerais, como da história bíblica. Em diversas passagens bíblicas estes materiais são citados e recorrentes, além de sua utilização em metáforas, constituem, portanto, elementos puros da natureza que, manipulados pelo ser humano, tomam forma e serventia.

A pedra como elemento de arrimo e edificação, que o tempo não desgasta ou destrói, mas se mantém e sustenta a casa. A água como elemento de purificação e contato com o Espirito Santo, que lava e santifica através dela. $E$ a madeira como elemento de construção, utilizada no tabernáculo e também de sustentação como deveras citada sob a forma de cajado.

Figura 6: Diagramas da planta, estrutura de cobertura e elevação.
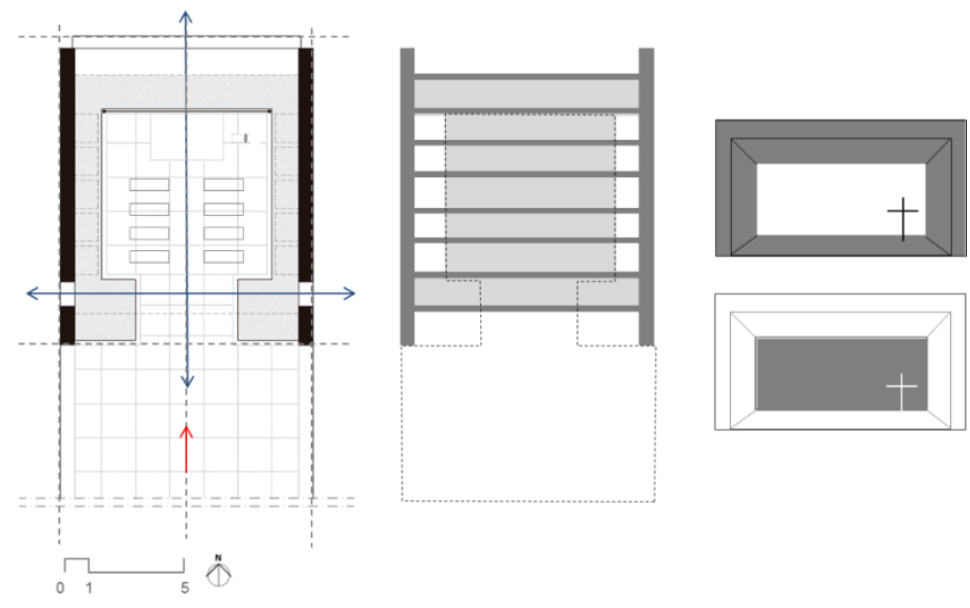

Fonte: Revista Projeto Design ${ }^{7}$, editado pela autora 
A iluminação é outro componente e elemento da arquitetura sacra que deve ser destacado nesta capela. $O$ eixo em que a capela está implantada permite grande insolação no altar, sendo esta a face mais iluminada a fachada norte, no entanto, as paredes laterais protegem a capela da exposição excessiva e permitem um jogo de luz com as aberturas da laje e o espelho d'água que reflete a luz. A iluminação natural é abundante, mas não ofuscante. A iluminação artificial é indireta, instalada no piso, ilumina a nave com a reflexão da luz sob a laje branca. As reflexões da iluminação através da materialidade aplicada, das cores utilizadas e da água dão o tom da proposta litúrgica à capela, na qual a arquitetura conduz ao clima de mistério, acolhimento, introspecção e reflexão, "sentimentos inerentes aos momentos de oração", como citam os arquitetos.

\section{CONSIDERAÇÕES FINAIS}

A análise das três capelas permitiu identificar algumas semelhanças e disparidades entre os objetos arquitetônicos. Nelas, repetidas vezes o termo "simples" foi utilizado para caracterizar o espaço, a concepção, o partido arquitetônico adotado. A pureza das formas e dos materiais notou-se constante em todos os estudos. Identifica-se o desejo dos arquitetos, em relação às suas obras, de revelar a arquitetura sagrada pela identidade própria da capela, sem que para isso dependa de associações espirituais com um estilo tradicional, ou seja, apesar de definida no inicio deste estudo a capela como "templo de pequena dimensão", após a análise dos exemplares ficou bastante claro que as capelas não se tratam de pequenas igrejinhas, ou igrejas de pequenas proporções tão somente. Mas tem liberdade arquitetônica de expressão, caráter sacro e não reproduzem simplesmente um espaço litúrgico de pequenas dimensões. Expressam mais, invocam mais, proporcionam mais àqueles que buscam uma experiência sob seu abrigo.

A arquitetura sacra ora analisada se mostra simples, livre de ornamentações, mas repleta de simbolismos e metáforas cuja percepção requer um olhar atento e até mesmo estudado quanto às sagradas escrituras. A parede de pedra, a presença da madeira e a iluminação no piso (de baixo para cima) são aspectos comuns às três capelas. $O$ crucifixo destoado em um dos lados do altar também é recorrente. A paisagem natural como continuidade, conjunto e componente da capela é escopo compartilhado destas três capelas, que não teriam igual ambiência e sentido se fora da natureza. A transparência arquitetônica, a ausência da materialidade e de imagens, traz à tona a fé intimista, faz com que seu frequentador esteja atento ao que vê e ao que sente, na simplicidade encontrada em meio à própria natureza, obra de Deus.

A fé intimista, de reflexão e contemplação é evidente e recorrente nestas capelas, onde a arquitetura corrobora para trazer á tona sensações e vislumbres que remetam ao fanum ora percebido do espaço profanum, que coexistem e se completam quando a arquitetura enquadra a paisagem natural e a paisagem natural faz fundo à transparência arquitetônica. A simplicidade e a transparência são características fundamentais destas arquiteturas para a intensificação da experiência e coexistência entre o homem e o divino.

O estudo da arquitetura sacra avança às questões técnicas e formais da análise arquitetônica, estendendose ao conteúdo simbólico e cognitivo da arte. As análises formais são essenciais ao entendimento e à caracterização da edificação, demonstram as relações internas, a organização espacial, o partido arquitetônico e funcionalidade do objeto estudado. No entanto, a percepção do espaço como um ambiente sagrado, onde a conexão com o ser divino pode ser estabelecida por intermédio da arquitetura produzida para este fim, tal como um receptáculo, não é tão óbvia. A percepção está relacionada com a interseção entre o sujeito e o objeto, não se faz individualmente como espaço qualificado para tal.

A Gestalt explora a teoria de que as experiências e carga emocional de cada indivíduo compõem o fenômeno da percepção, que é resultado de uma sensação global, cujas partes são indissociáveis. E por percepção aceitaremos o conceito introduzido por Padovano (1987, p.10) que a define como "aquisição de conhecimento de um determinado fenômeno, por meio dos sentidos (visão, olfato, tato, audição e paladar)". No entanto, o conceito não se encerra no repertório dos sentidos, há certa complexidade no processo perceptivo, sendo necessário considerar ainda outros fatores como o contexto, a cultura, a história e a experiência de cada sujeito.

Assim, estabelecer relações entre o espaço sagrado, que se configura como o ambiente que faz a conexão entre o homem e Deus e a arquitetura projetada para abriga-lo exige mais do que a análise formal e técnica. É essencial considerar as relações metafóricas e analógicas entre os meios fanum e profanum. Posto o conceito de percepção, fica claro que as relações não são necessariamente resultantes do pensamento dos arquitetos autores das obras analisadas, todavia negar a existência destas relações seria negligenciar o entendimento da arquitetura sagrada como um todo. 


\section{REFERÊNCIAS}

BAKER, Geoffrey. Le Corbusier: Uma análise da forma. São Paulo: Martins Fontes, 1998.

BÍBLIA SAGRADA. Traduzida em português por João Ferreira de Almeida. Revista e atualizada no Brasil. $2^{\mathrm{a}}$ ed.Barueri SP: Sociedade Bíblica do Brasil, 2008.

CHING, Francis D. K. Arquitetura: forma, espaço e ordem. São Paulo: Martins Fontes, 2008.

CLARK, Roger H.; PAUSE, Michel. Arquitectura: Temas de composición. México: Ed. Gustavo Gili, 1997.

CORBIOLI, Nanci. Vidro, madeira e pedra unidos em sutil composição. Projeto Design, São Paulo, ed. 333 , nov.2007. Disponível em: <https://arcoweb.com.br/projetodesign/arquitetu ra/beatriz-meyer-capela-tatui-18-12-2007>. Acesso em: 25 mar.2017.

CORONA, Eduardo; LEMOS, Carlos A. C. Dicionário da arquitetura brasileira. São Paulo: Edart - São Paulo Livraria Editora Ltda., 1998.

DURKHEIM, Émile. As formas elementares da vida religiosa. São Paulo: Martins Fontes, 1996.

FERNANDES, Gica. Capela Fazenda Veneza, Décio Tozzi. ArchDaily, 30.nov.2011. Disponível em: <http://www.archdaily.com.br/br/01-8658/capela-fazenda-veneza-decio-tozzi>. Acesso em: 25 mar.2017.

FREYRE, Gilberto. Casa-grande \& senzala: formação da família brasileira sob o regime da economia patriarcal. $48^{\circ}$ edição. São Paulo: Global, 2003.

MELENDEZ, Adilson. De três retas, surge a capela. Projeto Design, São Paulo, ed. 403, set.2013. Disponível em: <https://arcoweb.com.br/projetodesign/arquitetura/bl-arquitetura-capela-bom-despacho-mg>. Acesso em: 25 mar.2017.

MOTT, Luiz. Cotidiano e vivência religiosa: entre a capela e o calundu. In: SOUZA, Laura de Mello e (Org.). História da vida privada no Brasil: cotidiano e vida privada na América Portuguesa. São Paulo: Companhia das Letras, 1997. v. 1, cap. 4.

PADOVANO, Bruno R. Legibilidade da paisagem urbana: o caso de Santo Amaro. São Paulo: Tese (Doutorado em Arquitetura e Urbanismo), Faculdade de Arquitetura e Urbanismo da Universidade de São Paulo, São Paulo, 1987.

TOZZI, Décio. Capilla em la fazenda Veneza (São Paulo, Brasil). In: Actas del Congreso Internacional de Arquitectura Religiosa Contemporánea. N. 4, 2015. Disponível em: <http:/www.arquitecturareligiosa.es/index.php/AR/ article/view/145>. Acesso em: 25 mar.2017.

UNWIN, Simon. Analysing architecture. Nova lorque: Routledge, 1997.

WEISS, Raquel. Durkheim e as formas elementares da vida religiosa. Debates do NER, Porto Alegre, ano 13, n.22, p.95-119, jul/dez.2012.

\section{NOTAS}

1 Fanum: quer dizer templo, lugar sagrado; coisa sagrada. Aqueles que são iniciados numa religião dentro de um templo. De suas derivações surge o termo fanático do Latim fanaticus, entusiasta, "inspirado por algum deus", originalmente "relativo a um templo".

2 Profanum: aquilo que está à frente do fanum; que está em frente ao templo, que não entra nele; aquilo que está dividido e diferenciado de algo reconhecido como sagrado; que não pertence ao âmbito do sagrado. Quem não atendia a certas exigências religiosas estava "à frente" (pro, em Latim) do templo, ou seja, fora dele.

${ }^{3}$ Disponível em https://arcoweb.com.br/projetodesign/arquitetu ra/beatriz-meyer-capela-tatui-18-12-2007, acesso em 25 de março de 2017.

${ }^{4}$ RAMíREZ, Álvaro Niño. Cultos Pós Modernos. Revista Escala - Celebración, Memória y Culto. Bogotá, ano 46, n. 217, p. $13-16,2009$.

${ }^{5}$ Disponível em http://www.archdaily.com.br/br/01-8658/capela-fazenda-veneza-decio-tozzi, acesso em 25 de março de 2017.

6 Disponível em https://designbh.wordpress.com/2014/03/03/capela-fazenda-santa-helena-por-bl-arquitetura-santa-helena-farm-chapelby-bl-architecture/, acesso em 25 de março de 2017.

7 Disponível em https://arcoweb.com.br/projetodesign/arquitetura/bl-arquitetura-capela-bom-despacho-mg, acesso em 25 de março de 2017.

NOTA DO EDITOR (*) O conteúdo do artigo e as imagens nele publicadas são de responsabilidade do(s) autor(es). 